\title{
THE STRATEGIC POSITIONING OF THE PURCHASING FUNCTION WITHIN THE ORGANIZATIONS
}

\author{
Simona TOMA ${ }^{a^{*},}$ Alecxandrina DEACONU ${ }^{b}$ \\ ${ }^{a, b}$ Bucharest University of Economic Studies, Romania
}

\begin{abstract}
The purchasing department is perceived, more and more, as an important stakeholder within an organization structure. The position of the purchasing function in a well-organized company could reveal its importance acting as a strategical internal driver influencing finance, operations, social responsibility and human resources. However, the positioning of the purchasing function within the organization structure is yet to be identified. In the present paper we use in depth bibliographical documentation and semi-structured interviews performed with the management representatives of twelve companies within banking and pharmaceutical fields of activity. We found out that there is almost a consensus to place the purchasing department immediately under the hierarchy of the organization's top executive management. This trend will continue, as the purchasing function may bring benefits by supporting and influencing the business strategy.
\end{abstract}

KEYWORDS: strategic positioning, purchasing function, purchasing department, organizational structure.

DOI: $10.24818 / \mathrm{IMC} / 2021 / 04.12$

\section{INTRODUCTION}

The structure of a company defines how power and control are allocated inside the company and it has been strongly linked to the strategy and performance (Chandler, 1962).

The position of the purchasing department in the organizational structure (OS) may vary from a company to another. The purchasing department relationship with other internal stakeholders and the way it is perceived by them have great importance for the business results. Cooperation should not be just a rule of thumb inside the purchasing team project, but a constant exercise between the buyers and their internal partners. Everyone should be informed about the clear roles and responsibilities and aware about the organizational structure aligned with the companies' objectives. The purchasing positioning means the purchasing structure and its hierarchy, its interaction with other functions within organization.

Within an organization, usually the purchasing function has been focused on enhancing profitability, managing the associated risks within the supply chain, throughout the purchasing contracts lifetime and the entire relationship with the suppliers.

Syson (1992) emphasizes that the more purchasing department is involved in commercial and strategic areas within an organization rather than in the transactional ones, the greater will be its effectiveness within the organization. Additionally, it is hereby underlined that the level at which the purchasing function is placed in the hierarchical structure reveals its status within the company. The perception of various internal stakeholders upon this subject may be nowadays still under debate.

\footnotetext{
${ }^{*}$ Corresponding author. E-mail address: simo.toma@yahoo.com
} 
On the purchasers' side, their great majority tends to be comfortable with its responsibilities. However, most of the purchasing managers are confronted with the necessity to explain the value added of their job more often than other employees. Various factors lead to this situation. One reason could be when there are no clear positive results from their input, as sometimes the metrics of the purchasing process do not reveal a concrete influence on the profit and loss account, representing just cost avoidance. On the other hand, the purchasing department is usually blamed on if something may go wrong (worsen relationship with suppliers, no savings or impossibility to keep the pace with a cost-cutting budget and a modified consumption policy). Based on their expertise and the organization structure, the purchasing could coordinate or not the entire source to pay process.

On the internal partners' side, sometimes the purchasing department could not really be taken into consideration. Various causes may explain this. One of the reasons could be that some internal stakeholders might be unsatisfied with some general purchasing rules and principles (i.e. purchasers proposing organizing bids instead of direct negotiations with the same traditional suppliers, excessive focus on savings or the purchasers acting as single point of contact within the request for proposals, etc.). Another cause could be that sometimes they perceive purchasing department as invisible within a purchasing process, due to their prejudgments that purchasing could not help or the intention to speed up a process without taking into consideration all the risks that could be mitigated following the purchasing team advices. There are situations when some internal partners had been unsatisfied with some cost overruns or delays in finalizing the purchasing process performed with the purchasing team support.

At the management level, sometimes, there could not be promoted enough levers to involve the purchasing department from the origination of the budgets structure or when deciding upon the strategic projects roadmap, so that the purchasing function should be prepared to plan and execute a proper purchasing process. This means that not all the executive managers appreciate the benefits the purchasing team could bring. In addition to this, for some executives, it is relevant to discuss the outsourcing of the purchasing department.

Within our research, we have approached some managers in order to reach comparative analysis regarding the most appropriate positioning of the purchasing department within an organization, based on the experiences and strategies applied within companies.

\section{LITERATURE REVIEW}

The capacity to influence organizational outcomes was defined as power. Child (1972) underlines that the power is the key to strategic decisions.

Five sources of power were defined many years ago by French and Raven (1959): a/ organizational sources of power, depending on the position in the organizational hierarchy (i. e. reward power, legitimate power, coercive power) and $\mathrm{b} /$ individual power, depending on the personal characteristics, this being less removable from the holder (i. e. expert power and referent power). To those sources it was added informational source or persuasion, few years later (Raven, B.H., Social Influence and Power, 1965). After that, these sources of power were reanalyzed and developed like a new model, including various motivation of the influencing agent, utilization of various devices in stages to strengthen one's power resources, considerations of other strategies (i. e. manipulation), etc. (Raven, 1993). We may consider that there are cases when the importance of the purchasing function within the organization derives from the reputation of the head of purchasing or the team leaders for the competencies or likability of their personality to other stakeholders.

Apart from the power factor, according to Ibarra (1993), among other influential factors determining the status, there were identified the network centrality and the innovative involvement, the persons highly positioned within the organization being more likely to be successful innovators. 
All these can enhance the process focus, as part of the operational excellence (Năftănăilă et al., 2013).

Miles \& Cameron (1982) analyzed the role of the formal power in the strategic choices. They concluded that the diversification strategy is influenced by the power of different functional groups within organizations.

Based on the formal organizational structure, the structural power is linked to the hierarchical authority (Brass, 1984, Hambrick, 1981, Tushman and Romanelli, 1983).

Structural power is related to the distribution of formal positions within an organization. (Finkelstein, 1992).

Investigating historical reporting structures, the purchasing department was revealed as a function perceived as a transactional one, in charge with purchase orders processing and invoices exchanges. In this approach, it was defined more like an organizational unit responsible for carrying out some clerical functions with little influence throughout the organization. Sometimes, when price reductions were obtained, this was eventually well appreciated. That purchasing team commonly reported to lower level managers, part of the production division. Morris and Calantone (1992) particularly define the first stage of the purchasing evolution as a 'clerical' one, then evolving to the 'asset management and profitability' stage, up to the last ones, the 'core strategic' function stages. Emphasizing the evolution of the purchasing function, Syson (1992) mentions 'the changing focus of purchasing, as it evolves from a purely clerical routine activity to a commercial stage in which the emphasis is on cost savings and finally a proactive strategic function concerned with materials or logistic management'.

Reck and Long (1998) defined four different strategic stages of development regarding the purchasing function (i.e. passive, independent, supportive and integrative) and analyzed 12 related non-operational development variables. According to this development model, the authors emphasized that the purchasing may evolve from the 'passive' stage (purchasing perceived as a clerical function with limited career advancement, low organizational visibility reflected in the organizational chart structure, limited basis of resources availability, professional development focus deemed unnecessary) up to an 'integrative' stage (purchasing perceived as a strategic contributor with unlimited career advancement, high organizational visibility reflected in the organizational chart structure, strategic requirements related to the basis of resource availability, professional development focus on cross-functional understanding).

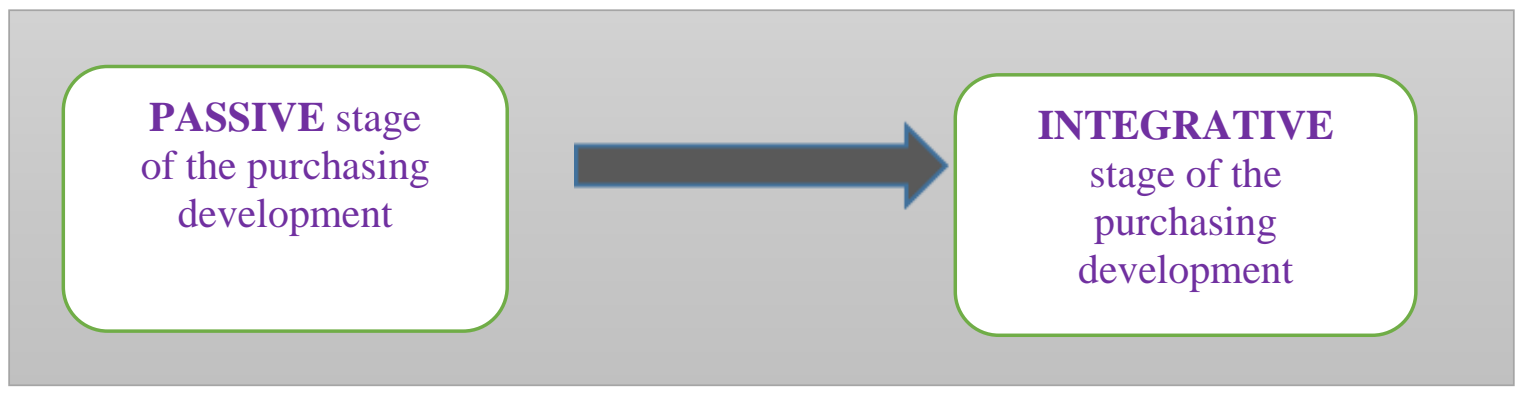

Figure 1. Evolution stages of the purchasing function

Source: adapted from Reck, R.F. and Long, B (1998)

The role within the organizations evolved due to the purchasing behavior. It is more and more perceived as an internal partner capable to create and develop relationships organizing competitive bid pricing and influencing the supply chain management. Its activities are nowadays linked to strategic cost management, sustainability, supplier-design development, integrating digital services within the supply chain; brief, the purchasing function must be ready to support the modern performance requirements. 


\section{METHODOLOGY}

The objective of our empirical research was to identify the proper positioning of the purchasing function within an organization and how this influenced the business strategy. The majority of the studies within the specialized literature upon the purchasing role, focus on large organizations. We also choose companies acting in some dynamic fields of activity, within banking and pharmaceutical sectors. Except for one organization, all of them are owned by multinational companies.

The method used was the qualitative analysis carried out by processing the answers coming from the participants.

The target group consists of 38 managers from 12 private companies within banking and pharma industries. They were ensured anonymity to encourage transparency of their internal practices. Out of the 38 managers, 21 were women $(55 \%)$ and 17 men $(45 \%)$. The majority of the interrogated participants $(75 \%)$ have more than 12 years senior management experience and interacted with purchasing department as internal stakeholders or direct managers, using strategical thinking when assessing the role of the purchasing function within their organizations.

Within the interviews performed, the main theme presented to the participants was that we aimed to investigate the role of the purchasing function within the structure of the companies and its influence in the business. The interaction with the participants was conceived in order to analyze both the:

$>$ Company's organizational structure, object of activity, yearly turnover, number of employees, shareholders structure, purchasing divisions' main responsibilities within the organization and the

Answers to open questions concerning the purchasing function role within organizations, focusing on significant elements of the participants' interaction with the purchasing department.

The questions contained statements related to the importance of the purchasing function within organizations. From their answers, a particular interest was in reaching our objective: how important it is perceived to be the purchasing department within their current organizational structure. The participants were addressed the following main questions, encouraging them to enlarge their answers to any related information that might contribute to deepening the comprehension of the subject.

The list of questions sent via email towards the participants:

i. Inside your companies, within the internal corporate governance, what is the usual place of the purchasing function? Please express if it should it be subordinated directly to the top management or reporting to another function for which it provides purchasing services.

ii. To what extent the position of the purchasing function within the structure of the organizational structure influenced the organization's efficiency during the hard times we face due to health crisis? Please provide relevant examples from the current activity. Please rank the importance of the function positioning in this regard on a scale from 1 to 3 (i.e. $1=$ low importance; 2 = medium importance; 3 = high importance).

iii. How should the purchasing management foster the influence of the purchasing function for the well-being of the organization? Please provide relevant examples from the current activity

iv. Which factors may influence the strategic positioning of the purchasing function within organizations?

The participants to the research were asked the above information via emails in a structured communication as of June 2021. The answers were received during June - July 2021. 
As of August 2021, on-line discussions were held with some of the participants in order to clarify some statements and to develop the theme. Due to the health crisis and their busy agenda, the online communication was preferred by all the interviewers, instead of the physical meetings.

The analysis of the answers was performed during August - September 2021.

\section{RESULTS}

By analyzing the answers to our interviews, we notice that effective positioning of the purchasing department is increasingly present on the business agenda. This is not kept at an anecdotic or informal level among different internal stakeholders. The subject evolves and its reverberations may go even outside the local organizations.

Related to the first aspect discussed, we found out that within the banking field, the purchasing department is usually positioned under the CFO hierarchy. Within the pharmaceutical field, the purchasing department is usually positioned under the CEO or CFO hierarchy or in the functional subordination of the regional organization. More than $70 \%$ of the participants emphasized the critical need for the purchasing department to keep its autonomy during the purchasing process, out of the internal stakeholders' potentially subjective influence. Their target should be fostering an optimum collaboration in order to be coherent with the general strategy of the organization, but keeping the pace with the general rules of purchasing. The independency of the purchasing function and an enforced cooperation with other departments is possible due to the strategic positioning of the purchasing function that is attached to the top management hierarchy.

As an additional explanation for the above, the participants also mentioned that the:

$\checkmark$ organizations studied have a great dimension in terms of total turnover, yearly spend, number of active suppliers managed and consequently an important coverage ratio of the total spend performed with the purchasing team intervention;

$\checkmark$ maturity level of the majority of the local purchasing functions within the majority organizations studied (90\%) is rather high, considering: a/ the local use of group's purchasing expertise; b/the local normative and the tools alignment with the group's principles and software; $\mathrm{c} /$ the risk policy put in place.

Related to the second aspect discussed, if the position of the purchasing function within the structure of the organizational chart influences the organizations' efficiency during hard times, most of the participants $(80 \%)$ considered that during hard times, when fast decisions are needed, the purchasing function directly contributed to the efficiency of the organization. Here are some findings:

Adjusted time to answer and the respect of the risk management principles are strong elements proving the implication of the purchasing team. Following the expansion of the sanitarian pandemic, have acquired sanitary materials and related equipment (i.e. for monitoring body temperature when entering a building) and IT equipment (i.e. laptops) to ensure the work from home. The purchasing team acts in an agile and collaborative way, understanding the crisis.

$\checkmark$ The position of the purchasing function within the organizational structure depends on the extent to which purchasing was previously perceived by top management as contributing to the competitive advantage.

$\checkmark$ Purchasing function acted as a significant contributor to the organization during the hard time we pass through the pandemic crisis especially when purchasing executives report directly to chief executive officers or if they put attention and sponsorship to particular projects arrived during turmoil situations.

$\checkmark$ The involvement of the purchasing department has the great chance to succeed when conditions, even during crisis, enable fully empowered teams motivated and focused on delivering results in due time; the participants presented some cases when more authority for 
the spend approval was given to the head of purchasing in order to speed-up the processes. Having top management sponsorship, the purchasing team received the proper mandate to act in an agile way and proving an outstanding time to answer, following their internal partner's request.

$\checkmark$ Due to risk management and purchasing category knowledge, the purchasers reached to obtain impressive results, by including awarding criteria or contractual clauses from the starting phase of the purchasing process.

$\checkmark$ When the purchasing department activity is enlarged and if it serves multiple business lines acting as a Shared Sourcing Services Center (SSSC), the outcome in terms of savings, cost avoidance and competitive advantage has been well received by their internal partners. Integrative practices and harmonized risk policies are important factors that lead to the management of simultaneous requests to organize bids. In the same time, the integration of purchasing and sharing the resources could be crucial elements during international disasters. With the SSSC put in place in two out of the twelve organizations studied, a strong advantage was created in order to make synergies and to have a better leverage of negotiation towards suppliers.

$\checkmark$ Global sourcing organizations, centralized networks and joint request for proposals also helped obtaining local efficiency, in some cases the local purchasing team having local hierarchical management and being functionally attached to the centralized global or regional entity outside the country.

Related to the third aspect discussed, the head of purchasing should have a series of qualities. The participants to the interview mentioned some of them, specifying that they are not limited to: diplomacy, perseverance to gain the wright place at the decision table, background not necessary within the purchasing field, adherence to a code of professional ethics.

Regarding the purchasing team's activity, the head of purchasing should:

$\checkmark$ Ensure dedicated category managers and resources; the purchasers should have skills based on theoretical knowledge (i.e. certified training, proven experience in the field and specialization on categories of purchasing (i.e. real estate, IT, professional services, etc.); all the above determine readiness and basis for the operational excellency needed expected by their internal partners;

$\checkmark$ Promote clear purchasing policies including basic rules with no ambiguities, but also updated in terms of ethical and environmental principles; the policies should describe virtually every aspect of purchasing activity, so that internal stakeholders should not try to avoid observing them because they did not understand some aspects.

In relation to the fourth aspect discussed, the analysis of the factors that may influence the strategic positioning of the purchasing function within organizations, we have reached the following conclusion resulted from the participants' answers:

$\checkmark$ There are some factors that might influence the importance of purchasing function both organizationally and within the entire supply chain. Among them, but not limited to, there are: the direct hierarchy of the head of purchasing, the total coverage baseline covered and the spend for which purchasing department is responsible, the job title, the strategic steering committees attended by the head of purchasing, etc.;

$\checkmark$ The position of the purchasing in the company's organizational structure depends on both strategic importance of purchasing to bring value added in qualitative (products, services) and quantitative terms (i.e. savings), and also the complexity of the supply market, which during pandemic times proves to be very difficult (i.e. supply scarcity, entry barriers, legislative or operational complexity, etc.).

$\checkmark$ The maturity level of the purchasing function and the agility to align to the business metrics may influence also the role within the organizational structure. 


\section{CONCLUSIONS}

Considering the actual COVID health crisis, as the research on emergency purchasing are few, we appreciate the authentic feedback of the participants, as they are facing different situations in their daily activity. The answers to our research are obtained within turmoil situation and we consider them relevant regarding the role that the purchasing department plays nowadays within different organizations as "Covid 19 has given businesses a push to make changes" (Ibarra, H., 2020).

We have reached our objective and we consider that it really matters weather the purchasing function reports to the top management or someone else in the organizational hierarchy. Throughout our analysis, we have objectively evaluated the answers of the participants that proved to know and interact a lot with the purchasing activity within their organizations.

The role of the purchasing function depends on its ability to influence positively the business being aligned with the corporate strategy. In the same time purchasing should bring tangible value to the profitability and the competitive advantage of the organization. If this target is achieved, nowadays the leadership of the purchasing function is usually consolidated under a head of purchasing that might have as direct report a vice-president or another representative of top-level executive that could be the chief financial officer, the chief operating officer or even the chief executive officer.

Head of purchasing directly reporting to top management executives is clearly in a stronger position to influence the company's efficiency than the one placed lower in the hierarchy, eventually reporting to production managers. A high position and a high status enable an effective approach for the purchasing implementation. Top management sponsorship helps to empower the function and encourage developing relationship with other departments.

The heads of purchasing directly reporting to the chief operations officer may have similar benefits to that of the chief executive officer relationship and could rely more to the product differentiation strategic positioning of the company. When purchasing function is attached to the chief financial officer, the benefits of process efficiencies could be outweighed by emphasizing some financial metrics that put pressure on the purchasing overall value creation within an organization. However, the strategic positioning of the purchasing function is linked to the company cost leadership strategy, with direct impact on the key performance indicators of the purchasing function.

The results of the analysis lead us to consider that the strategic positioning of the purchasing department will continue to evolve, as companies have to adjust a lot their business in the conditions in which the natural resources represent serious challenges for their development. Based on the strategy of the company, the purchasers might evaluate and mitigate the associated risks observing the sustainability standards of their products and services, aligned with the global objectives, i. e. UN Sustainable Development Goals to be achieved by 2030 (UN, 2015). This means the focus of the purchasing function is not only to obtain savings, but also on the possibility to facilitate sustainable value creation within organization, influencing the business environment.

Thus, nowadays the purchasing function plays an increasingly important role in the company's activity. Once the transition from transactional to tactical and finally to strategical purchasing is done, the purchasers have to be essentially changed managers looking forward to finding new opportunities for value creation within their organization facing surprising challenges (i.e. global health crisis).

Our research is limited due to the small number of companies that were analyzed through their representatives. The type of industry and its dynamics also influences the way purchasing departments are positioned within the organizational chart, or if there is outsourced or not.

As a continuation of our research upon the purchasing activity, we may further develop the analysis on areas such as the measurement indicators related to the supply chain risks, purchasing operational practices and ratios, globalization and strategic purchasing, challenges within the public purchasing structures, etc.). 


\section{REFERENCES}

Bras, D.J. (1984). Being in the right place: A structural analysis of individual influence in an organization. Administrative Science Quarterly, 29, 518-539.

Chandler, A. D. (1962). Strategy and Structure: Chapter in History of Industrial Enterprise. Cambridge. MA: MIT Press.

Child, J. (1972). Organizational Structure, Environment and Performance: The role of strategic choice. Sociology, 6, 1-22.

Finkelstein, S. (1992). Power in Top Management Teams: Dimension, Measurement and Validation, Academy of Management Journal, Vol.35, No.3, 505-538.

French, P., Jr., \& Raven, B. (1959). The basis of social power. Cartwright, D. (ed.). Studies in Social Power. Michigan Institute for Social Research.

Hambrick., D. C. (1981). Environment, strategy and power within top management teams. Administrative Science Quarterly, 26, 252-275.

Ibarra, H. (1993). Network centrality, power, and innovation involvement, determinants of technical and administrative power. Academy of Management Journal. Vol.36 (3), 471-502.

Ibarra, H., Leadership (in press). Financial Times, 09/02/2020.

Miles, R. H., \& Cameron, K. (1982). Coffin nails and corporate strategies. Englewood Cliffs. NJ: Prentice Hall.

Morris, N., \& Calantone, R. J. (1992). Redefining the purchasing function. International Journal of Purchasing and Materials Management, Fall.

Năftănăilă, I., Radu, C., \& Cioană, G. (2013). Operational Excellence - A Key to World Class Business Performance. Studies in Business and Economics, 8, 133-140.

Raven, B. H. (1965). Social Influence and Power. I.D. Steiner and M. Fishbein (Eds.). Current studies in social psychology, 371-381. New York: Holt, Rinehart, Winston.

Raven, B. H. (1993). The Basis of Power, Origins and Recent Developments. Journal of Social Issues, 49(4), 227-251.

Reck, R. F., \& Long, B. (1998). Purchasing, a competitive weapon. Journal of Purchasing and Materials Management, 24(3), p.4.

Syson, R. (1992). Improving Purchasing Performance. Pitman, 1992, pp.254-5.

Tushman, M. L., \& Romanelli, E. (1983). Uncertainty, social location and difference in decision making. Management Science, 28, 12-23.

United Nations (2015). The 2030 Agenda for Sustainable Development. https://www.un.org/sustainabledevelopment/development-agenda. 